\title{
EDUCACIÓN
}

\section{Estilo de gestión de los directores y docentes en los conflictos estudiantiles en la comunidad educativa de la Supervisión- Zona 2 de Educación Escolar Básica de Villarrica, Departamento Guaira, año 2016}

\author{
Alba Graciela Aguinagalde de Rodas ${ }^{1}$
}

\begin{abstract}
Resumen
Introducción: La investigación aborda una realidad de las instituciones educativas del Paraguay, específicamente a la forma en que se encara las situaciones de conflictos estudiantiles desde el sistema de autoridad institucional de los directivos, docentes y la supervisión ministerial de dicha área de influencia. La sociedad describe fenómenos sociales complejos que surgen de las dimensiones humanas y que repercuten en las conductas de sus miembros; por ello, este trabajo analiza las influencias de los conflictos estudiantiles que fueron observados en sus diversos tipos, tales como la violencia en sus diferentes formas, las agresividades y acosos estudiantiles todo ocurren dentro de las aulas e instalaciones de los centros de enseñanzas y fuera de las mismas que abarca la comunidad educativa de la Supervisión -Zona 2 de la Educación Escolar Básica de Villarrica, Departamento Guairá en el año 2016. La experiencia profesional y personal proporciona múltiples vivencias, que percibidas y sistematizadas como una oportunidad, dan la posibilidad de crecimiento individual, institucional y colectivo. Sin embargo no se puede soslayar que un importante grupo de supervisores, docentes, padres de familia y directores manifiestan que al realizar sus actividades correspondientes, se encuentran con situaciones con ambientes hostiles, falta de tolerancia, diálogo, compañerismo y respeto, y que a veces, viven un clima laboral pesado y llegan a emplear la mayor parte del tiempo en la búsqueda de soluciones a los problemas, originados por distintos conflictos.
\end{abstract}

Objetivo: Analizar el estilo de gestión educativa de los directores y docentes de situaciones educativas en los conflictos estudiantiles de la Supervisión-Zona 2, de Educación Escolar Básica de la ciudad de Villarrica, Departamento Guairá, año 2016.

Material y Método: Investigación descriptiva cuantitativa y cualitativa, utilizando la técnica de la encuesta para recabar las informaciones de los

1. Ministerio de Educación y Ciencias (MEC). Supervisión-Zona 2 E.E.B de Villarrica. Departamento Guairá.

E-mail: alba031@hotmail.es

DOI: $10.26885 /$ rcei.foro.2018.66

66 
directores y docentes, además se entrevistó a los integrantes de la EGI y la revisión documental.

Resultados: A partir de la revisión documental realizada en las instituciones se pudieron hallar los siguientes resultados: El 60\% de los Colegios tienen conformados el Equipo de Gestión Educativa y el 40 \% actúan de manera interna según los casos suscitados o de común acuerdo con las Supervisiones ante los casos de conflictos. Los Colegios no tienen redactado su propio reglamento escolar o las normas de convivencia escolar, la mayoría se orientan desde las disposiciones legales del MEC. Ninguna de las instituciones observadas tiene el protocolo de actuación ante los acosos escolares, tal como prevé la Ley $4633 / 12$. No se cuentan con registros de capacitaciones o especializaciones de directores y docentes para enfrentar las distintas situaciones de conflictos.

Conclusiones: La gestión institucional de directores y docentes para enfrentar los conflictos estudiantiles en los centros educativos dependientes de la Supervisión -Zona 2, no son de alta gerencia por carencia de liderazgos educativos. En cuanto al estilo, existe falta de la organización, planificación escolar ante las presencias de situaciones de conflictos, lo cual indica que resulta necesario que cada institución educativa esté preparada en establecer una nueva reingeniería de la planificación y de la organización educativa apropiada para orientar los conflictos estudiantiles. Hay déficit en la conformación plena del EGI, de la normativización desde el protocolo de atención al acoso escolar, lo cual dificulta una atención inmediata a todos los conflictos escolares. Se puede enfatizar la poca consolidación del protocolo de atención al acoso en instituciones tratadas, lo cual genera un vacío legal de tratar acuerdos con la comunidad educativa.

Palabras clave: gestión, liderazgo educativo, conflictos, estrategias.

\section{Referencias}

Arnaiz, P. Jesús, S. (1998). La tutoría, ¿̇area de quién? y la programación de la acción tutorial. En La tutoría, organización y tareas. Barcelona: Editorial Graó.

Bajtín, M. (1990). Introducción. Planteamiento del Problema. En La cultura popular en la edad media y en el renacimiento.

Benjamín, W. (1989). La Obra de Arte en la Época de su Reproductividad Técnica. En Discursos interrumpidos I. Buenos Aires: Taurus.

De Brasi, J. C. (1987). Desarrollos sobre el Grupo-Formación. En AA.VV. Lo Grupal. Buenos Aires: Ediciones Búsqueda.

Echeverría, B. (2004). Caminar en relación: tutorías personalizadas en la universidad. Letras de Deusto, 34(103), 189-205. 